American Journal of Pharmacology and Toxicology 6 (4): 102-106, 2011

ISSN 1557-4962

(C) 2011 Science Publications

\title{
Interaction of Aqueous Extract of Trigonella Foenum-Graecum Seeds with Glibenclamide in Streptozotocin Induced Diabetic Rats
}

\author{
${ }^{1}$ Lal, V.K., ${ }^{2}$ P.P. Gupta, ${ }^{3}$ P. Tripathi and ${ }^{3}$ A. Pandey \\ ${ }^{1}$ Department of Pharmacy, SITM, Barabanki, India \\ ${ }^{2}$ Department of Pharmacology, BRDM College, Gorakhpur, India \\ ${ }^{3}$ Research Scholar, UTU, Dehradun, India
}

\begin{abstract}
Problem statement: Interaction between herbs and drugs may increase or decrease the pharmacological or toxicological effects of either component. Herb traditionally used to decrease glucose concentrations in diabetes could theoretically precipitate hypoglycaemia if taken in combination with conventional drugs. Approach: The present study was undertaken to determine the interaction of Glibenclamide, a Sulphonylurea with Trigonella foenum-graecum seed extract, an herbal drug widely used as a antidiabetic agent. The pharmacodynamic interaction was evaluated in streptozotocin induced diabetic rats. Glibenclamide was given orally in two different doses of 0.25 and $0.50 \mathrm{mg} \mathrm{kg}{ }^{-1}$. Trigonella seed extract was administered at a dose of $20 \mathrm{~mL} \mathrm{~kg}^{-1}$. The blood glucose estimation was carried out. Results: Both glibenclamide and Trigonella seed extract showed hypoglycemic effect. The hypoglycemic effect observed with combination of glibenclamide and Trigonella seed extract was significantly more than either of drug given alone. Conclusion: It is concluded that Trigonella seed extract shows synergistic effect with glibenclamide. This could be important in reducing the dose of glibenclamide to achieve enhanced therapeutic effect with minimum adverse effect.
\end{abstract}

Key words: Glibenclamide, trigonella foenum-graecum, hypoglycemic, synergistic effect

\section{INTRODUCTION}

Diabetes Mellitus (DM) is a major chronic lifethreatening disorder, in which homeostasis of carbohydrate and lipid metabolism is improperly regulated by the pancreatic hormone, insulin; resulting in an increased blood glucose level. DM is a serious metabolic disease that has a significant impact on the health, quality of life and life expectancy of patients, as well as on the health care system Sancheti et al. (2009). The condition affects the metabolism of carbohydrates, fat, water and electrolytes leading to structural changes in a range of cells especially those of the vascular system, subsequently leading to long term complications of diabetes (King et al., 1998; Amos et al., 1997; Zimmet, 2000; Kumar and Clark, 2002; Wild et al., 2004). On the basis of laboratory findings, WHO has defined DM as a fasting venous plasma glucose concentration greater than $7.8 \mathrm{~m} \mathrm{~mol} / \mathrm{lt}\left(140 \mathrm{mg} \mathrm{dL}^{-1}\right)$ or greater than $11.1 \mathrm{~m} \mathrm{~mol} / \mathrm{lt}\left(200 \mathrm{mg} \mathrm{dL}^{-1}\right)$, two hours after carbohydrate meal or two hour after an oral ingestion of the equivalent of $75 \mathrm{~g}$ glucose, even if the fasting condition is normal (Grossman and Messerli, 1996).
It is also one of the most prevalent (the estimated lifetime risk of developing diabetes for individuals born in 2000 is $32.8 \%$ for males and $38.5 \%$ for females) and costly chronic diseases, which significantly reduces life expectancy. In the year 2000, the total number of people with DM was 151 million and the number is projected to increase by $46 \%$ to reach 221 million by the year 2010 and 300 million in 2025 Al-Shamsi et al. (2007). Most of these cases will be type 2 diabetes, which is strongly associated with a sedentary lifestyle and high calorie-nutrition and obesity (Zimmet et al., 2001; 2003).

This presents a moving therapeutic target that requires a range of different agents to address the different features of the disease at different stages of its natural history. Although biomedical science has unrevealed substantially the pathologically processes involved in causing/fostering diabetes and has designed therapeutic agents with a range of action to fight hyperglycemia, the efficacy of these therapeutic agents is compromised in several ways. Individual agents act only on part of the pathogenic process and only to a 
partial extent. This may be the reason that even after so much advancement in understanding the disease process and availability of a wide range of therapeutic agents, the disease is still progressing.

Although several drugs targeted for carbohydrate hydrolysing enzymes (pseudosaccharides), release of insulin from pancreatic b-cells (sulphonyl urea), glucose utilization (biguanides), insulin sensitizers, PPAR $\alpha$ agonists (glitazones) are in clinical practice, the growing diabetes market observes a number of changes. The glitazones are meant to target the problem of insulin resistance and enhance insulin action at the cellular level; however, some of these drugs are linked to liver toxicity (troglitazone), including a number of deaths from hepatic failure (Krische, 2000; Gale, 2001; Stern, 1999) and raising the symptoms and risk factors of heart disease leading to heart failure (rosiglitazone).

Use of Complementary and Alternative Medicine (CAM) in the United States has been increasing in recent years (Eisenberg et al., 1998). Indeed, the dietary supplement industry is currently estimated to be a $\$ 20$ billion industry and according to recent statistics from the Food and Drug Administration (FDA), there are at least 29,000 dietary supplement products on the market. Dietary supplements are defined by the Dietary Supplement and Health Education Act (DSHEA) of 1994 Anon, 1995 and include such products as herbals, vitamins, minerals, sports nutrition supplements, weight management products, specialty supplements and other oral dosage forms intended to supplement the diet.

Hence antidiabetic herbs are also utilized frequently and effectively. A multitude of plants have been used for the treatment of DM throughout the world. In fact in many parts of world especially in poor countries, this may be the only form of therapy available for treating diabetic patients. Complementary and alternative medicine involves the use of herbs and other dietary supplements as alternatives to mainstream Western medical treatment. A recent studies has estimated that up to $30 \%$ of patients with DM use complementary and alternative medicine (Ryan et al., 2001).

The interaction of herbs with drug is well known. Herbal drug interaction can be characterized as either Pharmacodynamic (PD) or Pharmacokinetic (PK) in nature. Pharmacodynamic interaction may occur when constituents of herbal product have either synergistic or antagonistic activity in relation to a conventional drug. Pharmacokinetic interaction result from alteration of absorption, distribution, metabolism or elimination of a conventional drug by an herbal product or other.

Seeds of Trigonella Foenum-graecum L. (Leguminosae) are known to exhibit hypoglycemic activity when taken orally. The hypoglycemic effect of Trigonella seeds and their major alkaloids, trigonilline was first described by Fournier and by Nadakarnis. The seeds are widely recommended for non insulin dependent diabetes mellitus patients. Ajabnoor and Tilmisany reported the hypoglycemic effect of Trigonella foenum graecum seeds on the serum glucose level (Abdel-Barry et al., 1997).

Now a day many people use the antidiabetic herb and antidiabetic drug along with and hence there may be chance of interaction between them. Thus the present study was undertaken to evaluate any possible pharmacodynamic interaction Trigonella seed extract with oral hypoglycemic agent named glibenclamide.

\section{METERIALS AND METHODS}

Plant material: Trigonella foenum-graecum (Fenugreek) seeds were purchased from the local market and identified by the NBRI, Lucknow, India. A voucher specimen no is 97378 .

Extraction of aqueous plant material: About $100 \mathrm{~g}$ of powdered Trigonella foenum- graecum seeds were added in $750 \mathrm{~mL}$ of boiling water and macerated well for $10 \mathrm{~min}$. The $400 \mathrm{~mL}$ final filtrate was then cooled, filtered, stored as aqueous extract at $4^{\circ} \mathrm{C}$ and used for oral administration.

Experimental animal: Healthy adult rats of wistar strain weighing $110-160 \mathrm{mg}$ were used in the present study. The animals were housed in clean polypropylene cages and maintained in a well ventilated temperature controlled animal house with constant $12 \mathrm{~h}$ lightldark schedule. The animals were fed with standard rat pellet diet and clean drinking water was made available ad libitum.

\section{Experimental design:}

Induction of diabetes: Rats were fasted overnight before inducing diabetes with streptozotocin. The rats were given an intraperitoneal injection of streptozotocin $\left(50 \mathrm{mg} \mathrm{kg}{ }^{-1}\right.$ ) freshly prepared in $0.1 \mathrm{M}$ sodium citrate buffer. The diabetic state was confirmed $48 \mathrm{~h}$ after streptozotocin injection. Threshold value of fasting blood glucose was taken as $>200 \mathrm{mg} \mathrm{DL}^{-1}$.

Control and diabetic rats were weighed matched for body weight and divided into following group consisting five animal each:

Group I-Non diabetic control: Treated with single ip injection vehicle 
- Group II-Diabetic Control: Administrated orally with equal volume of vehicle alone

- Group III-Diabetic rats administered with extract of Trigonella foenum graecum seed at a dose of 2 $\mathrm{mL} 100 \mathrm{~g}^{-1}$ body weight $\backslash$ day

- Group IV-Diabetic rats administered with Glibenclamide at low dose of $0.25 \mathrm{mg} \mathrm{kg}^{-1}$

- Group V-Diabetic rats administered with Glibenclamide at high dose of $0.5 \mathrm{mg} \mathrm{kg}^{-1}$

- Group VI-Diabetic rats administered with Fenugreek extract and low dose of Glibenclamide

- Group VII-Diabetic rats administered with Fenugreek extract and high dose of Glibenclamide

Blood glucose estimation: Blood sample was obtained through puncture tail vein and glucose was estimated on $0,7,14,21$ and 28th day by Accu-Check Glucometer.

Statistical analysis: Result were expressed as mean \pm SEM. Statistical analysis was carried out by using one way analysis of variance followed by Dunnet test. A value of $\mathrm{p}<0.05, \mathrm{p}<0.01$ and $\mathrm{p}<0.001$ were considered significant.

\section{RESULTS}

The mean blood glucose level of animals at various time intervals after the oral administration of drug, extract and drug extract combinations are shown in Table 1. The glucose levels were compared to values obtained for animals given only normal saline (Diabetic control).

Aqueous extract of Fenugreek seeds showed significant decrease $(\mathrm{p}<0.05)$ in blood sugar level in comparison to diabetic control group. Glibenclamide alone and the combination of extract and glibenclamide caused a steady and significant reduction in the glycemia throughout the duration of the monitoring period as shown in Fig. 1. Table 1 showed that aqueous extract of Fenugreek seeds significantly increase the hypoglycemic effect of half dose of glibenclamide and its nearby similar to the hypoglycemic effect obtained by glibenclamide high dose. The maximum hypoglycemic effect was seen by the high dose of glibenclamide with aqueous extract of Fenugreek seeds.

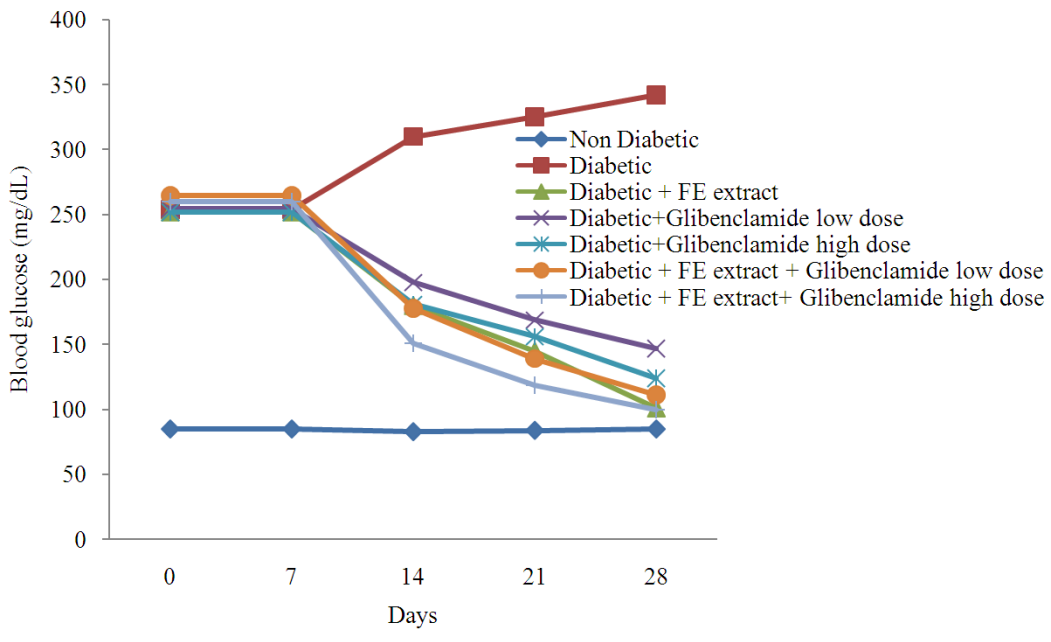

Fig. 1: Effect of Trigonella seed extract, Glibenclamide and Glibenclamide + Trigonella seed extract on blood glucose

Table 1: Effect of Trigonella seed extract, Glibenclamide and Glibenclamide + Trigonella seed extract on blood glucose

\begin{tabular}{|c|c|c|c|c|c|}
\hline \multirow[b]{2}{*}{ Groups } & \multicolumn{5}{|c|}{ Blood glucose } \\
\hline & 0 day & 7 day & 14 day & 21 day & 28 day \\
\hline Non Diabetic & $90 \pm 3.9$ & $93 \pm 4.6$ & $91 \pm 2.6$ & $94 \pm 3.5$ & $89 \pm 2.7$ \\
\hline Diabetic & $235 \pm 2.7$ & $281 \pm 3.5$ & $297 \pm 4.6$ & $333 \pm 4.8$ & $327 \pm 5.1$ \\
\hline Diabetic + Trigonella seed extract & $227 \pm 4.6$ & $215 \pm 3.2 *$ & $168 \pm 2.6^{*}$ & $129 \pm 5.2 *$ & $120 \pm 3.7 *$ \\
\hline Diabetic + Glibenclamide low dose & $229 \pm 3.2$ & $203 \pm 3.3^{*}$ & $162 \pm 3.6^{*}$ & $121 \pm 3.8^{*}$ & $113 \pm 4.1 *$ \\
\hline Diabetic + Glibenclamide high dose & $244 \pm 3.2$ & $203 \pm 6.2 * *$ & $159 \pm 4.2 * *$ & $119 \pm 4.8 * *$ & $99 \pm 2.3 * *$ \\
\hline Diabetic + Trigonella seed extract + Glibenclamide low dose & $233 \pm 4.6$ & $185 \pm 5.8 * *$ & $131 \pm 2.8 * *$ & $110 \pm 2.6^{* *}$ & $105 \pm 3.7 * *$ \\
\hline Diabetic + Trigonella seed extract+ Glibenclamide high dose & $233 \pm 3.7$ & $179 \pm 3.8 * * *$ & $123 \pm 3.7 * * *$ & $98 \pm 3.9 * * *$ & $71 \pm 2.9 * * *$ \\
\hline
\end{tabular}

All values are expressed as mean \pm S.E.M $(\mathrm{n}=5) . \quad * \mathrm{p}<0.05, * * \mathrm{p}<0.01, * * * \mathrm{p}<0.001$ as compared to diabetic control. One-way ANOVA followed by Dunnet test 


\section{DISCUSSION}

Many medicinal plants and pharmaceutical drugs are therapeutic at one dose and toxic at another. Interaction between herbs and drugs may increase or decrease the pharmacological or toxicological effects of either component. Synergistic therapeutic effects may complicate the dosing of long term medications e.g., herb traditionally used to decrease glucose concentrations in diabetes could theoretically precipitate hypoglycaemia if taken in combination with conventional drugs.

The present study was undertaken to evaluate the effect of aqueous extract of Fenugreek seeds on hypoglycemic activity on hypoglycemic action of glibenclamide. The result observed suggest that aqueous extract of Fenugreek seeds when combined with glibenclamide enhances the hypoglycemic activity of latter.

The combination of high dose of glibenclamide $\left(0.5 \mathrm{mg} \mathrm{kg}{ }^{-1}\right)$ with aqueous extract of Fenugreek seeds shows maximum hypoglycemic activity and the effect produced by the combination of glibenclamide $(0.25$ $\mathrm{mg} \mathrm{kg}^{-1}$ ) with aqueous extract of Fenugreek seeds was similar to hypoglycemic effect shown by glibenclamide alone $\left(0.5 \mathrm{mg} \mathrm{kg}^{-1}\right)$.

It is likely that the beneficial effect of TE is due to some of the bioactive compounds present in it, including 4-hydroxyisoleucine, a novel amino acid known to facilitate insulin secretion. In addition, the soluble dietary fibers present in TE could inhibit absorption of glucose in the gastrointestinal tract (Xue et al., 2007).

Glibenclamide is used to treat DM. Sulphonylurea enhance cell insulin release by blocking the ATPdependent $\mathrm{K}^{+}$channel and are widely used in the treatment of type 2 diabetes-mellitus. In chronic therapy the mechanism of action of Sulphonylurea is less clear. Studies have shown that the long-term use of these oral hypoglycaemic agents does not increase basal insulin release or enhance insulin secretion in response to metabolic stimuli in patients with type 2 diabetes, the drug has been described as a classical inhibitor of the $\mathrm{K}^{+}{ }_{\text {ATP }}$ channels in pancreatic $\beta$ cells whose target is the SUR receptor, a protein belonging to the $\mathrm{ABC}$ transporter family (Anon, 1995).

Administration of an antidiabetic herb with a hypoglycemic drug for the treatment of diabetes may pose for potential drug-herb interaction that may have beneficial or adverse effects. It is generally believed that the use of herbs with medicine produces enhanced effect and reduces the adverse effect of drugs. The results of the present study indicate that combining aqueous extract of Fenugreek seeds with glibenclamide could provide an opportunity to reduce the dose of glibenclamide, which may help in minimizing the adverse effect of glibenclamide as well as achieve enhanced therapeutic effect. At the same time proper precaution and care should be taken to avoid severe hypoglycemia that may occur due to combination of these agents.

\section{CONCLUSION}

Furthermore this observed synergistic effect has a great clinical implication. A diabetic patients on be placed on a reduced dose of glibenclamide (Which also implied lower adverse effect) while being encouraged to consume Trigonella seed extract. The issue of interaction should be seriously considered while a patient is combining a potent antidiabetic agent and herbal remedies. So caution should be taken if any patient is taking antidiabetic drug and herb as this might cause severe hypoglycemia which could lead to coma and ultimately death.

\section{REFERENCES}

Abdel-Barry, J.A., I.A. Abdel-Hassan and M.H.H. AlHakiem, 1997. Hypoglycaemic and antihyperglycaemic effects of Trigonella foenumgraecum leaf in normal and alloxan induced diabetic rats. J. Ethnopharmacol., 58: 149-155. DOI: 10.1016/S0378-8741(97)00101-3

Al-Shamsi, M., A. Amin and E. Adeghate, 2007. The effect of vitamin $\mathrm{C}$ on the metabolic parameters of experimental diabetes mellitus. Am. J. Pharmacol. Toxicol., 2: 4-9. DOI: 10.3844/ajptsp.2007.4.9

Amos, A.F., D.J. McCarty and P. Zimmet, 1997. The rising global burden of diabetes and its complications: Estimates and projections to the year 2010. Diabetic Med., 14: S7-S85. DOI: 10.1002/(SICI)1096-

9136(199712)14:5+<S7::AID-DIA522>3.3.CO;2-I

Anon, 1995. Dietary supplement health and education act of 1994. U. S. Food and Druq Administration Cantre for Food Safety and Applied Nutrition.

Eisenberg, D.M., R.B. Davis, S.L. Ettner, S. Appel and S. Wilkey et al., 1998. Trends in alternative medicine use in the united states, 1990-1997: Results of a follow-up national survey. J. Am. Med. Assoc., 280: 1569-1575. DOI: 10.1001/jama.280.18.1569

Gale, E.A.M., 2001. Lessons from the glitazones: A story of drug development. Lancet, 357: 18701875. DOI: 10.1016/S0140-6736(00)04960-6 
Grossman, E. and F.H. Messerli, 1996. Diabetic and hypertensive heart disease. Ann. Intern. Med., 125: 304-310. PMID: 8678395

King, H., R. Aubert and W.H. Herman, 1998. Global burden of diabetes, 1995-2025: Prevalence, numerical estimates and projections. Diabetes Care, 21: 1414-1431. DOI: 10.2337/diacare.21.9.1414

Krische, D., 2000. The glitazones: Proceed with caution. West J. Med., 173: 54-57. PMID: 10903299

Kumar, P. and M.L. Clark, 2002. Clinical Medicine. 5th Edn., W.B. Saunders Company, London, ISBN-10: 0702025798, pp: 1464.

Ryan, E.A., M.E. Pick and C. Marceau, 2001. Use of alternative medicines in diabetes mellitus. Diabet Med., 18: 242-245. DOI: 10.1046/j.14645491.2001.00450.x

Sancheti, S., S. Sancheti and S.Y. Seo, 2009. Chaenomeles Sinensis: A potent $\alpha$-and $\beta$ glucosidase inhibitor. Am. J. Pharmacol. Toxicol., 4: 8-11. DOI: 10.3844/ajptsp.2009.8.11

Stern, M.P., 1999. On the need for outcome trials in preventive pharmacology. Diabetes Care, 22: 844845. DOI: $10.2337 /$ diacare.22.5.844
Wild, S., G. Roglic, A. Green, R. Sicree and H. King, 2004. Global prevalence of diabetes estimates for the year 2000 and projections for 2030. Diabetes Care, 27: 1047-1053. DOI: 10.2337/diacare.27.5.1047

Xue, W.L., X.S. Li, J. Zhang, Y.H. Liu and Z.L. Wang et al., 2007. Effect of Trigonella foenum-graecum (fenugreek) extract on blood glucose, blood lipid and hemorheological properties in streptozotocininduced diabetic rats. Asia Pac. J. Clin. Nutr., 16: 422-426. PMID: 17392143

Zimmet, P., 2000. Globalization, coca-colonization and the chronic disease epidemic: Can the Doomsday scenario be averted? J. Int. Med., 247: 301- 310. DOI: 10.1046/j.1365-2796.2000.00625.x

Zimmet, P., J. Shaw and K.G.M.M. Alberti, 2003. Preventing type 2 diabetes and the dysmetabolic syndrome in the real world: A realistic view. Diabet Med., 20: 693-702. DOI: 10.1046/j.14645491.2003.01052.x

Zimmet, P., K.G.M.M. Alberti and J. Shaw, 2001. Review article global and societal implications of the diabetes epidemic. Nature, 414: 782-787. DOI: $10.1038 / 414782 \mathrm{a}$ 